\title{
Dietary trends in the Middle East and North Africa: an ecological study (1961 to 2007)
}

\author{
Mahdieh Golzarand ${ }^{1}$, Parvin Mirmiran ${ }^{2, *}$, Mahsa Jessri $^{1}$, Karamollah Toolabi $^{3}$, \\ Mehdi Mojarrad' ${ }^{1}$ and Fereidoun Azizi ${ }^{4}$ \\ 'Obesity Research Center, Research Institute for Endocrine Sciences, Shahid Beheshti University of Medical \\ Sciences, Tehran, Islamic Republic of Iran: ${ }^{2}$ Department of Clinical Nutrition and Dietetics, Faculty of Nutrition \\ Sciences and Food Technology, Shahid Beheshti University of Medical Sciences, No. 46 Arghavan-e-gharbi \\ Street, Farahzadi Blvd, Shahrak-e-Ghods, Tehran, Islamic Republic of Iran: ${ }^{3}$ Department of Surgery, Imam \\ Khomeini Hospital, Tehran University of Medical Sciences, Tehran, Islamic Republic of Iran: ${ }^{4}$ Endocrine \\ Research Center, Research Institute for Endocrine Sciences, Shahid Beheshti University of Medical Sciences, \\ Tehran, Islamic Republic of Iran
}

Submitted 6 June 2011: Accepted 13 December 2011: First published online 9 February 2012

\begin{abstract}
Objective: Middle Eastern and North African countries are undergoing nutrition transition, a transition which is associated with an increased burden of noncommunicable diseases. This necessitates the evaluation of dietary patterns in these regions. The present study aimed to assess changes in dietary patterns in Middle Eastern and North African countries between 1961 and 2007.

Design: Availability of energy and fifteen main food items during 1961-2007 was examined using FAO food balance sheets from the FAOSTAT database.

Setting: Fifteen countries including nine in the Middle East and six in North Africa were selected and the average availability of total energy and different food items in these regions were compared.

Results: Over the 47 years studied, energy and food availability (apart from animal fats and alcoholic beverages) has increased in the Middle East and North Africa. In both regions the proportion of energy derived from meat and vegetable oils has increased significantly while that from cereals decreased significantly. In addition, the proportion of energy from milk and dairy products and vegetables has shown an ascending trend in North Africa while the proportion of energy from fruits has shown a descending trend in the Middle East.

Conclusions: The study results reveal an unfavourable trend towards a Westernized diet in the Middle East and, to a certain extent, in North Africa. Tailored nutritional education encouraging healthy eating for prevention of the burden of chronic diseases in these countries seems essential.
\end{abstract}

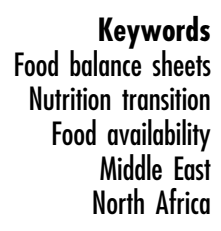

Nutrition transition is a global change in the quality and quantity of dietary patterns ${ }^{(1)}$, and is characterized by high consumption of energy, fat (especially of animal origin), added sugars and salty foods and low intakes of complex carbohydrates, dietary fibre, fruits and vegetables $^{(2)}$. Nutrition transition commonly coincides with a decrease in physical activity ${ }^{(3)}$. Among the several factors that have contributed to the development of nutrition transition worldwide, the effects of globalization on income and lifestyle is a major contributor. Globalization also affects food availability by changing food production, providence and distribution systems ${ }^{(4)}$. In addition, a rapid shift in demographic characterization, urbanization and social improvement, without steady economic growth, has resulted in food availability changes and nutrition transition ${ }^{(5)}$. These factors together with increased industrialization and mechanization that have occurred in most countries are associated with changes in dietary patterns and lifestyle practices $^{(6)}$.

Nutrition transition is a common modifiable cause of non-communicable diseases (NCD) through its changing of dietary patterns ${ }^{(7)}$. During the past two decades, several studies in the Middle East and North Africa have shown an alarming increase in the prevalence of overweight and obesity, which are associated with CVD, type 2 diabetes, IHD, hypertension and several types of cancer $^{(4,5,8-10)}$. Table 1 presents the increase in the burden of NCD between 1990-2003 and 2010 in the Middle East and North Africa ${ }^{(11,12)}$. The burden of NCD in developing countries is reported to be $77.9 \%{ }^{(13)}$, despite high prevalences of malnutrition disorders (including protein-energy malnutrition, Fe-deficiency anaemia and iodine-deficiency 
Table 1 The burden of non-communicable diseases (\%) over the last two decades in the Middle East and North Africa ${ }^{(11,12)}$

\begin{tabular}{|c|c|c|c|c|c|c|c|c|c|c|}
\hline \multirow[b]{2}{*}{ Country } & \multicolumn{2}{|c|}{ Overweight } & \multicolumn{2}{|c|}{ Obesity } & \multicolumn{2}{|c|}{ Hypertension } & \multicolumn{2}{|c|}{ Diabetes } & \multicolumn{2}{|c|}{ Hypercholesterolaemia } \\
\hline & 1990-2003 & 2010 & 1990-2003 & 2010 & 1990-2003 & 2010 & 1990-2003 & 2010 & 1990-2003 & 2010 \\
\hline Iran & $58 \cdot 4$ & $55 \cdot 0$ & $21 \cdot 1$ & $21 \cdot 6$ & $10 \cdot 0$ & $39 \cdot 4$ & $5 \cdot 9$ & $9 \cdot 9$ & $23 \cdot 6$ & $54 \cdot 1$ \\
\hline Jordan & $44 \cdot 0$ & $68 \cdot 6$ & $34 \cdot 8$ & $34 \cdot 3$ & $16 \cdot 1$ & $35 \cdot 1$ & $13 \cdot 4$ & $17 \cdot 7$ & $30 \cdot 3$ & $48 \cdot 8$ \\
\hline Kuwait & $64 \cdot 2$ & $79 \cdot 3$ & $28 \cdot 8$ & $42 \cdot 8$ & $5 \cdot 9$ & $38 \cdot 4$ & $14 \cdot 8$ & $16 \cdot 2$ & $53 \cdot 4$ & $56 \cdot 2$ \\
\hline Lebanon & - & $62 \cdot 8$ & $17 \cdot 0$ & $28 \cdot 2$ & $22 \cdot 8$ & $40 \cdot 4$ & $11 \cdot 6$ & 11.9 & $18 \cdot 4$ & - \\
\hline Saudi Arabia & $63 \cdot 9$ & $71 \cdot 3$ & $27 \cdot 0$ & $35 \cdot 2$ & $26 \cdot 1$ & $41 \cdot 4$ & $23 \cdot 7$ & $21 \cdot 8$ & $15 \cdot 7$ & $18 \cdot 1$ \\
\hline Syria & $56 \cdot 3$ & $66 \cdot 4$ & $22 \cdot 5$ & $31 \cdot 6$ & $28 \cdot 8$ & - & - & - & $33 \cdot 5$ & - \\
\hline United Arab Emirates & $54 \cdot 8$ & $72 \cdot 0$ & $15 \cdot 3$ & $33 \cdot 7$ & $22 \cdot 0$ & 38.9 & - & $15 \cdot 5$ & - & - \\
\hline Yemen & - & - & - & - & - & - & - & - & - & - \\
\hline Algeria & - & $42 \cdot 8$ & $16 \cdot 4$ & $17 \cdot 5$ & $27 \cdot 6$ & 43.5 & $6 \cdot 0$ & $9 \cdot 2$ & $36 \cdot 5$ & $39 \cdot 4$ \\
\hline Egypt & $47 \cdot 5$ & $69 \cdot 8$ & $14 \cdot 5$ & $34 \cdot 6$ & $26 \cdot 3$ & $38 \cdot 1$ & $7 \cdot 2$ & $7 \cdot \overline{2}$ & $19 \cdot 4$ & $39 \cdot 9$ \\
\hline Libya & - & $65 \cdot 4$ & - & $30 \cdot 8$ & $22 \cdot 5$ & $49 \cdot 6$ & $14 \cdot 1$ & $14 \cdot 4$ & - & $14 \cdot 4$ \\
\hline Morocco & $28 \cdot 8$ & $48 \cdot 5$ & $16 \cdot 0$ & $17 \cdot 3$ & $39 \cdot 6$ & $45 \cdot 0$ & $8 \cdot 4$ & - & 33.9 & $37 \cdot 2$ \\
\hline Sudan & - & - & - & - & - & - & - & - & - & - \\
\hline Tunisia & $52 \cdot 5$ & 55.9 & $24 \cdot 3$ & $23 \cdot 8$ & $15 \cdot 0$ & $42 \cdot 0$ & $6 \cdot 5$ & $40 \cdot 7$ & $16 \cdot 9$ & $40 \cdot 7$ \\
\hline
\end{tabular}

disorders) in these countries ${ }^{(4,14)}$. The high prevalence of NCD worldwide, especially in the Middle East and North Africa, has been attributed to rapid changes in the structure of dietary patterns ${ }^{(2,4,13,15-17)}$. Findings from several studies that investigated changes in dietary patterns in the European Union, Latin American and Mediterranean countries ${ }^{(6,18-20)}$ have revealed similar patterns of dietary change and food availability worldwide. In all the regions mentioned, an increase in sugar, animal products and fat intakes and a decrease in the availability of vegetable products have been documented, and these dietary changes have been associated with the burden of NCD in these countries. However, in most developing countries, food policy has focused merely on food insufficiency and not on the prevention of $\mathrm{NCD}^{(21)}$; although the burden of malnutrition, $\mathrm{NCD}$ and mortality is high in the Middle East and North Africa, changes in the dietary patterns in these regions have rarely been assessed. The present ecological study aimed to evaluate changes in dietary patterns in the Middle East and North Africa regions from 1961 to 2007.

\section{Methods}

According to geographic location the Middle East region includes Bahrain, the Islamic Republic of Iran (Iran), Iraq, Jordan, Kuwait, Lebanon, Oman, Palestine, Qatar, Saudi Arabia, Syria, the United Arab Emirates and Yemen. However, data for four countries were not available in the FAOSTAT database; hence Iran, Jordan, Kuwait, Lebanon, Palestine, Saudi Arabia, Syria, the United Arab Emirates and Yemen were included in the present study. North African countries include Algeria, Egypt, Morocco, Libya, Sudan and Tunisia.

\section{Database}

In the present study, to avoid inter-country errors and variations, food availability data in the Middle East and North Africa from 1961 to 2007 were obtained from the
FAO's food balance sheets documented in the FAOSTAT database ${ }^{(22)}$. The food balance sheet is compiled annually and is an international resource of a country's food availability during a certain period ${ }^{(20,22)}$. Food availability is derived from production, supply, different usages and wastages of food and indicates apparent consumption instead of real consumption ${ }^{(19,23)}$. Assessing the trend in availability of food components is a useful tool for evaluation of changes in dietary patterns and can applied to defining dietary patterns ${ }^{(24-26)}$. For the calculation of food availability in a country, the amount of food exported, used for animals and in agriculture or wasted is subtracted from the amount of food produced and imported; the annual amount of available energy from food items is then divided by the total population of a country in the same period. Per capita food availability data are represented as $\mathrm{kcal} /$ person per $\mathrm{d}$ in the FAOSTAT database ${ }^{(24)}$.

In the present study, regional differences and trends in food supply were evaluated for fifteen staple foods including cereals, starchy roots, sugar and sweeteners, pulses, nuts, oil crops, vegetable oils, vegetables, fruits, animal fats, meat, eggs, milk, fish and seafood, and alcoholic beverages. A list of the fifteen staple foods and food items included in the different food categories is presented in the Appendix.

In terms of determination of socio-economic status (SES) in countries of the Middle East and North Africa, data on gross domestic product (GDP) per capita from The World Bank were used. According to this, countries with GDP per capita of less than \$US 1005 were classified as low income, \$US 1006-3975 as lower-middle income, \$US 3976-12 795 as upper-middle income and over \$US 12976 as high income (Table 2). Energy and food items availability were then analysed within different SES.

\section{Statistical analyses}

All data were analysed using the SPSS statistical software package version 15 (SPSS Inc., Chicago, IL, USA). Food availability was reported as mean and standard deviation. 
Table 2 Per capita gross domestic product (GDP), purchasing power parity (PPP) and socio-economic status (SES) in 2007 in the Middle East and North Africa. Data are from The World Bank ${ }^{(46)}$

\begin{tabular}{lccl}
\hline & $\begin{array}{c}\text { Actual per capita GDP, } \\
\text { 2007 (\$US) }\end{array}$ & $\begin{array}{c}\text { Gross national income PPP, } \\
\text { 2007 (\$US) }\end{array}$ & SES \\
\hline Middle East & & & High income \\
United Arab Emirates & 47565 & - & High income \\
Kuwait & 43087 & 53630 & High income \\
Saudi Arabia & 15881 & 23020 & Upper-middle income \\
Lebanon & 6020 & 11040 & Upper-middle income \\
Iran & 4028 & 10880 & Lower-middle income \\
Jordan & 3130 & 5340 & Lower-middle income \\
Syria & 2012 & 4410 & Low income \\
Yemen & 972 & 2200 & \\
North Africa & & & Upper-middle income \\
Libya & 11639 & 16130 & Upper-middle income \\
Algeria & 4011 & 7670 & Lower-middle income \\
Tunisia & 3483 & 7130 & Lower-middle income \\
Morocco & 2373 & 3960 & Lower-middle income \\
Egypt & 1630 & 5110 & Lower-middle income \\
Sudan & 1153 & 1830 & \\
\hline
\end{tabular}

Trends of food availability in the Middle East and North Africa during the period studied (1961-2007) were analysed using time series; while the independent-samples $t$ test was used to compare means between the Middle East and North Africa in each period. One-way ANOVA was used to compare means between different SES and a two-tailed $P$ value of $<0 \cdot 05$ was considered statistically significant.

\section{Results}

Availability of energy and main food items in the Middle East and North Africa from 1961 to 2007 is shown in Fig. 1. Availability of energy and all food items assessed (except for alcoholic beverages in the Middle East and North Africa, and animal fats in the Middle East) has increased during the 47 years. Energy availability increased by $42 \cdot 2 \%$ and $60 \cdot 8 \%$ in the Middle East and North Africa, respectively. Although total energy availability was higher in the Middle East compared with North Africa $(P=0 \cdot 01)$ in the 1960s, it increased faster in North Africa than in the Middle East during the 47 years under study (Fig. 1). We found that the proportion of total energy derived from carbohydrates decreased in both regions (from 68\% to 63\% in the Middle East and from $71 \%$ to $67 \%$ in North Africa), while the proportion of energy from fat increased (from $21 \%$ to $26 \%$ in the Middle East and from $18 \%$ to $22 \%$ in North Africa) and the proportion of energy from protein remained constant (11\%; Table 3).

\section{Cereals}

Cereals were the staple food in the Middle East and North African countries between 1961 and 2007 (Table 3). At baseline, there were no significant differences in cereal availability between the two regions $(P=0 \cdot 22)$; however, during the 47 years of the study, the availability of cereals in the Middle East and North Africa increased by 992 (SD 904) and 2201 (SD 753) kJ/person per d (237 (SD 216) and 526 (sD 180) kcal/person per d), respectively (Fig. 2). During the 47 years the proportion of total energy derived from cereals decreased significantly in the Middle East (from $57 \cdot 2 \%$ to $48 \cdot 8 \%$ ) and North Africa (from $62 \cdot 9 \%$ to $56 \cdot 6 \%$; Fig. 3). Regardless of the different categories of SES in each region, a similar trend was found in all countries.

\section{Fruits and vegetables}

In the 1960s, the availability of fruits and vegetables was higher in the Middle East than North Africa $(P<0 \cdot 05)$; however, in 2007, there was no significant difference in their availability between the two regions (Fig. 1). During the 47 years of study, the availability of fruits and vegetables increased in both regions, but the increase was more dramatic in North Africa than the Middle East (fruits: 193 (SD 141) v. $80(\mathrm{SD} 305) \mathrm{kJ} /$ person per $\mathrm{d}(46 \cdot 1$ (SD 33.8) $v .19 \cdot 2(\mathrm{sD} 72 \cdot 8)$ $\mathrm{kcal} /$ person/d); vegetables: 245 (SD 116) v. 133 (SD 233) kJ/ person per d $(58.5(\mathrm{SD} 27 \cdot 7) v .31 \cdot 8(\mathrm{SD} 55 \cdot 7) \mathrm{kcal} /$ person/d), respectively; Fig. 2). This increase was found in all income categories except for lower-middle income countries in the Middle East where availability of fruits and vegetables decreased. Between 1961 and 2007, the total energy derived from fruits decreased in the Middle East from 5.6\% to $4 \cdot 4 \%$, mainly due to reduced availability in lower-middle income countries, but in North Africa there was no trend $3.6 \%$ at both time points). The proportion of energy from vegetables increased both in the Middle East and North Africa during the 47 years under study (Fig. 3); this increase was found in all countries with different SES. In both regions, fruit and vegetable consumption was lower than the minimum recommended value of $400 \mathrm{~g} / \mathrm{d}$ during the study period ${ }^{(19)}$.

\section{Meat and pulses}

This food group comprises meat, eggs, fish and seafood, pulses and nuts. The availability of meat and pulses in the 1960s differed between the Middle East and North Africa 

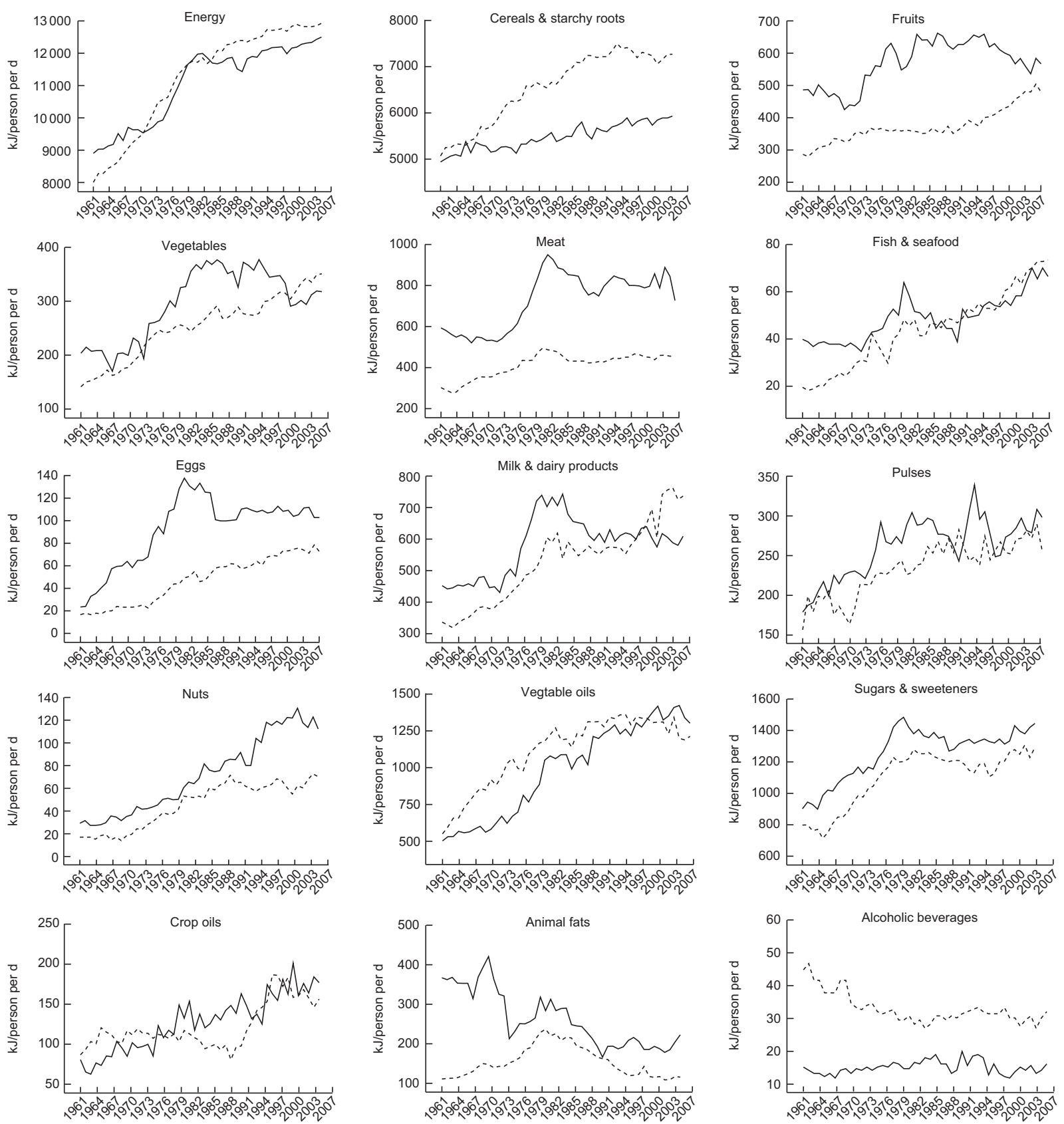

Fig. 1 Daily per capita availability of energy and food groups in the Middle East ( - ) and North Africa (- - - ) during $1961-2007$. Data are from FAO food balance sheets, FAOSTAT database ${ }^{(22)}$

$(P<0.05)$ but the availability of these food items has increased in both regions over the 47 years. In 2007 the availability of meat, eggs and nuts was higher in the Middle East than North Africa, while the availability of pulses, fish and seafood was the same in both regions (Fig. 1). During the period under review, the amount of energy derived from meat and pulses increased steadily and significantly in the Middle East (from 9.3\% to 11.6\%) and North Africa (from 6.5\% to $7 \cdot 4 \%$; Fig. 3). With respect to SES, the availability of meat and pulses and the proportion of energy from this group showed a similar increasing trend in all income categories. In 2007, the
Middle East, but not North Africa, consumed the minimum recommended amount of meat (Table 3) ${ }^{(19)}$.

\section{Milk and dairy products}

During the 1960s, the availability of milk was higher in the Middle East than in North Africa $(P<0 \cdot 05)$; it increased by 386 (SD 260) and 168 (SD 308) kJ/person per $\mathrm{d}(92 \cdot 3(\mathrm{sD} 62 \cdot 1)$ and $40 \cdot 1(\mathrm{sD} 73 \cdot 6) \mathrm{kcal} / \mathrm{person} / \mathrm{d})$ in North Africa and the Middle East, respectively, with no significant difference being observed in 2007 between the two regions (Figs 1 and 2). From 1961 to 2007, the proportion of energy from milk to total energy intake 
Table 3 Recommended daily dietary intakes and actual dietary intakes in the Middle East and North Africa

\begin{tabular}{|c|c|c|c|c|c|}
\hline \multirow[b]{2}{*}{ Dietary component } & \multirow{2}{*}{$\begin{array}{l}\text { Recommended dietary } \\
\text { intake range }\end{array}$} & \multicolumn{2}{|c|}{ Middle East } & \multicolumn{2}{|c|}{ North Africa } \\
\hline & & 1961 & 2007 & 1961 & 2007 \\
\hline Energy (kJ) & 9205 & 8878 & 11933 & 8004 & 12786 \\
\hline Energy (kcal) & 2200 & 2122 & 2852 & 1913 & 3056 \\
\hline Total carbohydrate (\% of energy) & $55-75$ & 68 & 63 & 71 & 67 \\
\hline Protein (\% of energy) & $10-15$ & 11 & 11 & 11 & 11 \\
\hline Total fat ( $\%$ of energy) & $15-30$ & 21 & 26 & 18 & 22 \\
\hline Cereals (servings) & 9 & 15 & 17 & 15 & 22 \\
\hline Fruits (servings) & 3 & 1.9 & $2 \cdot 1$ & $1 \cdot 1$ & 1.9 \\
\hline Vegetables (servings) & 4 & $2 \cdot 1$ & $3 \cdot 4$ & 1.5 & $3 \cdot 7$ \\
\hline Meats (servings) & 2 & $1 \cdot 5$ & $2 \cdot 5$ & 0.8 & $1 \cdot 6$ \\
\hline Milk (servings) & $2-3$ & 0.8 & $1 \cdot 1$ & 0.6 & $1 \cdot 4$ \\
\hline Free sugars ( $\%$ of energy) & $<10$ & 10 & 12 & 10 & 10 \\
\hline
\end{tabular}

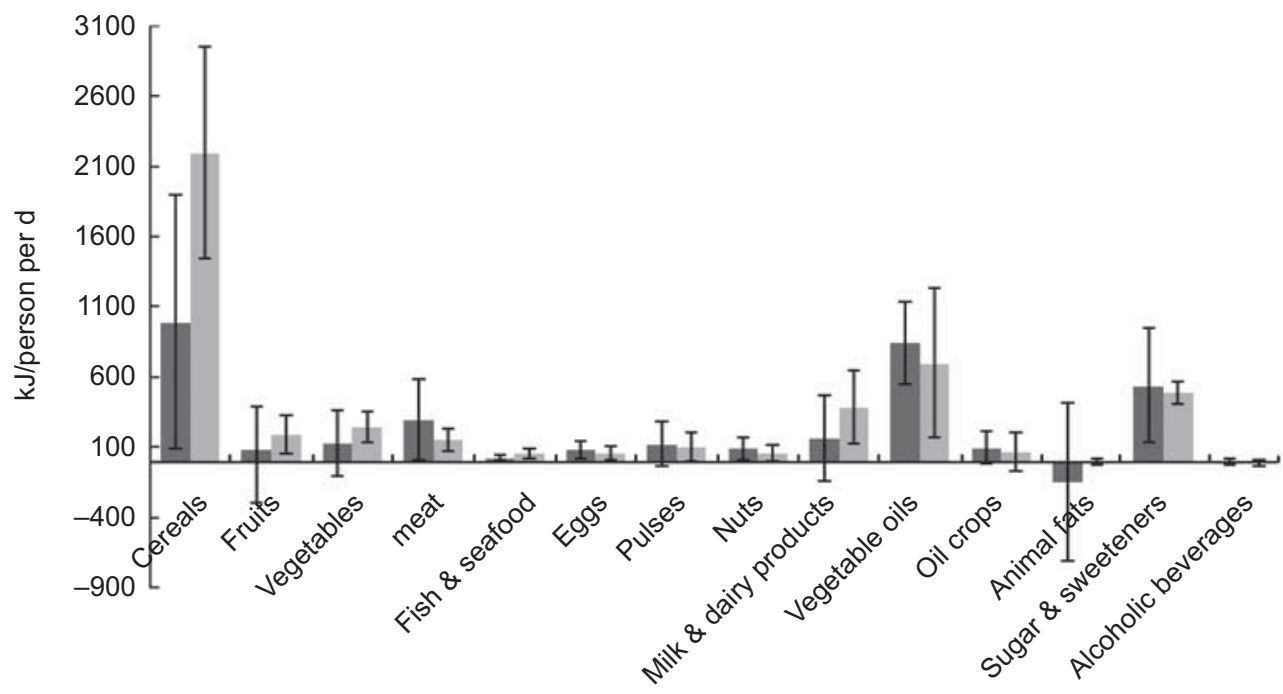

Fig. 2 Changes in the availability of food groups during 1961-2007 in the Middle East $(\square)$ and North Africa ( $\square$ ). Values are means with their standard deviations represented by vertical bars. Data are from FAO food balance sheets, FAOSTAT database ${ }^{(22)}$

increased in North Africa (from $4 \cdot 4 \%$ to $6 \cdot 1 \%$ ), whereas it remained constant in the Middle East (from $4 \cdot 7 \%$ to $4 \cdot 8 \%$; Fig. 3). The same trend was found in the different SES groups in the Middle East and North Africa. However, both regions failed to meet the minimum recommended dietary intake values for milk (Table 3) ${ }^{(19)}$.

\section{Vegetable oils}

The availability of vegetable oils showed no significant differences between the Middle East and North Africa during the study period (Fig. 1). Over the 47 years under study, the availability of vegetable oils increased steadily to 920 (sD 293) and 699 (sD 531) kJ/person per d (220 (SD 70) and 167 (SD 127) kcal/person/d) in the Middle East and North Africa, respectively (Fig. 2). The availability of oil crops also increased over the 47 years (Fig. 1), but there were no significant differences in their availability between the Middle East and North Africa during the study period (Fig. 2). From 1961 to 2007, the proportion of energy from oils (both vegetable and oil crops) increased steadily in the Middle East (from 6.5\% to
$12 \cdot 3 \%$ ) and North Africa (from $8 \cdot 0 \%$ to $10 \cdot 8 \%$; Fig. 3). Increases in the availability of oils and the proportion of energy from oils were found in all income categories.

\section{Sugar and sweeteners, animal fats and alcobolic beverages}

During the 1960s, the availability of sugar and sweeteners and animal fats was higher, while that of alcoholic beverages was lower in the Middle East compared with North Africa. Between 1961 and 2007 the availability of sugar and sweeteners increased steadily in a similar pattern in both regions (Fig. 1), while in the Middle East, the availability was higher than in North Africa (542 (SD 405) v. $494(\mathrm{sD} 80) \mathrm{kJ} /$ person per $\mathrm{d}(129 \cdot 7$ ( $\mathrm{SD}$ 96.8) v. $118 \cdot 0$ (sD 19.1) kcal/person/d; Fig. 2); in both regions consumption of free sugars was higher than the maximum recommended value (Table 3$)^{(19)}$

On the other hand, although the availability of animal fats and alcoholic beverages decreased more in the Middle East than in North Africa over the 47 years under study (Figs 1 and 2), in 2007 the availability of alcoholic 

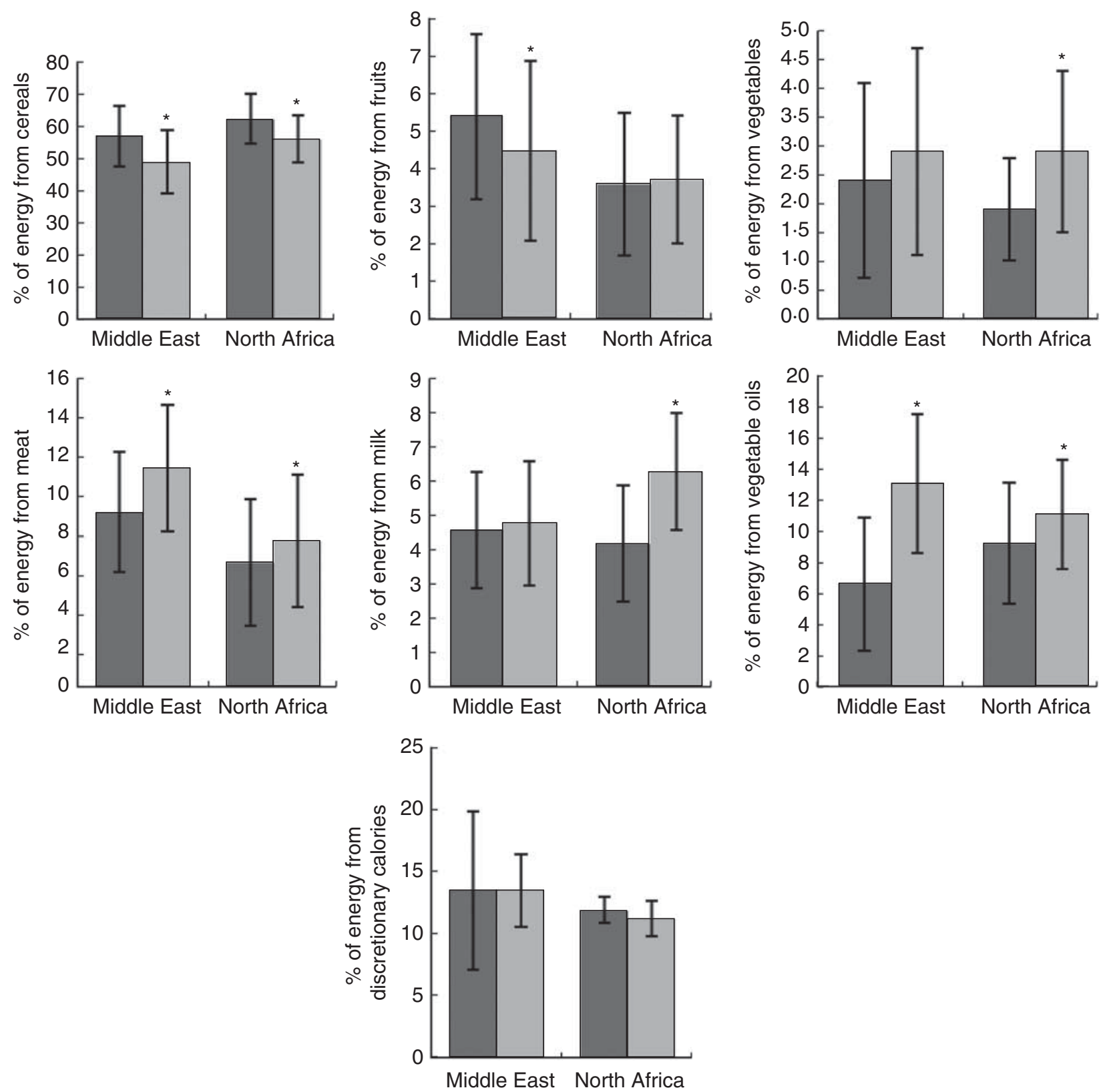

Fig. 3 Changes in the proportion of energy from food groups during 1961-2007 ( $\square$, 1961-1966; $\square$, 2003-2007) in the Middle East and North Africa. Values are means with their standard deviations represented by vertical bars. Mean values within a region were significantly different from those in 1961-1966: ${ }^{*} P<0 \cdot 05$. Data are from FAO food balance sheets, FAOSTAT database ${ }^{(22)}$

beverages was higher in North Africa and that of animal fats was higher in the Middle East. The proportion of discretionary calories in total energy intake remained steady during 1961-2007 in the Middle Eastern (13.5\%) and North African countries (11.0\%; Fig. 3). Discretionary calories are defined as the energy derived from added sugars, solid fats and alcoholic beverages ${ }^{(27)}$.

\section{Discussion}

In the present paper we report changes in dietary patterns in the Middle Eastern and North African countries from
1961 to 2007. Our results show that the availability of energy and all food items has increased in both regions during the last half century, a finding in agreement with previous reports ${ }^{(6,19,25,28)}$. In North Africa most of the changes were related to increases in the availability of eggs (7-fold), fish and seafood (3.5-fold), oil crops (3-fold) and nuts (3-fold), while in the Middle East most of the changes were due to increases in the availability of vegetables (4.5-fold), nuts (4-fold), eggs (4-fold) and vegetable oils $(3 \cdot 5$-fold). During the 47 years under study, the availability of energy in the Middle East and North Africa increased by $42 \%$ and $61 \%$, respectively. Over the 
past four decades studies have shown that per capita energy availability has increased significantly in developing countries, by approximately $2500 \mathrm{~kJ} / \mathrm{d}(600 \mathrm{kcal} / \mathrm{d})^{(29)}$; this has more significance when considering the fact that several studies suggest the energy requirement of people from developing countries is low ${ }^{(30)}$. This dramatic increase indicates a transition from undernutrition towards overnutrition in these regions, resulting in rising rates of obesity and other chronic diseases ${ }^{(10,13)}$.

In the present study, despite the ascending trend of cereal availability, the proportion of energy from cereals decreased between 1961 and 2007 in both regions. The slowing population growth and nutrition transition are the most probable causes of reduced intakes of cereals ${ }^{(6)}$. However, data from food balance sheets show only the availability of total cereals and starchy roots, not the availability of whole or refined grains; and hence changes in the availability of whole and refined grains over the 47 years are unknown. Nevertheless, Atinmo et al. ${ }^{(4)}$ have reported that consumption of refined grains is increasing in the Middle East and North Africa, which could be attributed to globalization and the high availability of modern processed foods ${ }^{(31)}$

Our findings indicate that the availability of fruits and vegetables increased in the Middle East and North Africa ${ }^{(19)}$. Da Silva et al. ${ }^{(23)}$ have indicated that adherence to the Mediterranean dietary pattern increased between the periods of 1961-1965 and 2000-2003 in North Africa and some countries of the Middle East, mainly due to increased availability of fruits and vegetables, the most common cause of which is the increased diversity of fruits and vegetables worldwide ${ }^{(19)}$. In addition, owing to the inverse association between fruit and vegetable consumption and chronic diseases ${ }^{(32-34)}$, most countries have increased their availability of fruits and vegetables to improve healthy eating and prevent chronic diseases ${ }^{(19)}$. In spite of increased availability of fruits and vegetables, however, current consumption of these food groups is low in both the Middle East and North Africa and does not meet the FAO's recommended intake value of $400 \mathrm{~g} / \mathrm{d}$. In recent years, due to land and water shortages and the low demand for agricultural products, the availability of plant-based foods has declined in some countries.

Between 1961 and 2007, the availability of meats and milk showed an increasing trend in the Middle East and North Africa. Increased demand for and production of meat, fish and milk in developing countries may have contributed to the elevated availability of these foods items in the two regions. According to the International Food Policy Research Institute, the greatest production and consumption of meats and milk takes place in developing countries, predicted to reach to $63 \%$ and $50 \%$, respectively, by 2020 in these countries ${ }^{(35)}$. In addition, increasing imports of these food groups also has affected their availability ${ }^{(2)}$. However, the availability of meat in North Africa and of milk in both North Africa and the Middle East is below the minimum recommended values, which could explain the high prevalence of malnutrition disorders, particularly Fe-deficiency anaemia and protein-energy malnutrition, in these regions.

The availability of vegetable oils and their proportional contribution to total energy have both increased in the Middle East and North Africa during the 47 years of the study. In recent decades, consumption of vegetable oils has increased dramatically worldwide ${ }^{(7)}$, being the greatest contributor to increased total energy intake in developing countries. Globally, the low price of vegetable oils may have led to their increased consumption ${ }^{(29)}$. In most developing countries, technological advances, increased production and the high demand and import are responsible for increased availability of vegetable oils. Global production of vegetable oils increased from 60 to 71 million tonnes between 1991 and 1997, while production of animal fats has remained constant, at approximately 12 million tonnes ${ }^{(24)}$. The most commonly produced vegetable oils are soyabean, sunflower, canola and mixed groundnut ${ }^{(7)}$. Global availability of these oils, with the exception of mixed groundnut oil, increased threefold between 1961 and 1990 (35). In addition, urbanization (particularly in Africa and Asia), shift in economic status (especially income increases and inequalities) and the globalization of media have affected the availability of vegetable oils ${ }^{(36)}$. However, it seems that an increase in modern food consumption, including fast foods, could be the major cause of high vegetable oil intakes ${ }^{(19)}$, which increases total fat consumption and leads to obesity and chronic disease morbidity ${ }^{(37)}$.

Availability of discretionary calories in the Middle East and North Africa was at the limit recommended by the US Department of Agriculture during the 47 years under study (12-20\% of total daily energy) ${ }^{(27)}$. Despite the positive correlations between intake of sugar and sweeteners and chronic diseases, consumption of caloric sweeteners shows an ascending trend in the Middle East and North Africa as well as in other countries around the world. In 2000, the availability of sugar and sweeteners was three times higher than in 1961. Urbanization and increased GDP of a country contribute to high availability of caloric sweeteners ${ }^{(34)}$. In addition, traditions of high consumption of tea and coffee with sugar in the Middle East and North Africa can also contribute to the elevated sugar consumption ${ }^{(38)}$. In the 47 years studied, availability of discretionary calories has shown no significant difference. Despite the increase in sugar and sweeteners, the decrease in availability of animal fats and alcoholic beverages in the Middle East and North Africa is responsible for the lack of change in availability of discretionary calories in both regions. Lower intakes of alcoholic beverages in these regions are due to religious beliefs and traditions ${ }^{(24)}$.

Overall, the traditional diet of North Africa is based on the Mediterranean diet which includes high consumption of fruits, vegetables, cereals, beans, nuts, seeds and olive oil, moderate consumption of wine, low to moderate 
consumption of cheese, yoghurt, fish, poultry and eggs, and low consumption of red and processed meats ${ }^{(39)}$. Over the 47 years studied, although North Africans have sustained the basic components of their traditional diet such as fruits, vegetables and pulses consumption, their intakes of sugar and vegetable oils have increased. Middle Eastern countries have also deviated from their traditional dietary patterns which consisted mainly of cereals, pulses, vegetables, fruits and lamb. Our findings show that after 47 years, the availability of fruits and cereals has decreased, while the availability of meat, sugar and vegetable oils has increased. There is a relationship between high consumption of sugars and fats and increased consumption of fast foods, processed and high-energy foods, which has occurred as a result of nutrition transition in developing countries $^{(40)}$. High consumption of sugars and vegetable oils is the major contributor to the increased total energy intake, which may in turn account for the alarming rise in NCD prevalence in the Middle East and North Africa. Previous studies have demonstrated that nutrition transition is associated with unhealthy diets, low physical activity, high prevalence of obesity and obesity-related diseases in developing countries ${ }^{(39)}$. The Middle East and North Africa are undergoing nutrition transition and although some shifts in their dietary patterns have been beneficial, including increased supply and availability of foods, others have been detrimental, associated with the development of chronic diseases ${ }^{(5)}$. In the developing countries, nutrition transition has predisposed higherincome groups to the risk of obesity and diet-related diseases, while low-income groups are exposed to infectious and communicable diseases, although some also suffer from overweight and obesity due to nutrition transition ${ }^{(41)}$. Deviations from healthy dietary patterns can be an adverse effect of nutrition transition. According to WHO recommendations, the Mediterranean diet represents a healthy dietary pattern ${ }^{(24)}$ and several studies have demonstrated the protective effect of the Mediterranean diet against chronic diseases ${ }^{(42-45)}$. Therefore, nutritional education on the importance of a healthy diet at the population level and developing policies to facilitate the availability of healthy foods could reduce the rapid trend of obesity and other chronic diseases.

The FAO food balance sheet does have its limitations. First, the food balance sheet represents only the energy available for consumption, and not real consumed values $^{(19)}$. It overestimates energy availability in developing countries, while underestimating it in developed countries. Second, the food balance sheet shows energy per capita and does not allow for comparisons according to age, sex, SES, seasonal and regional differences; moreover, the sheet does not calculate home-made production and food consumption by tourists. However, despite the limitations, the food balance sheet is a costeffective tool for longitudinal comparisons; and although it is not the only source of data for consumption at population level, it is still the best available data source for analysis during a specific period a time for any given country $^{(23)}$.

\section{Conclusions}

It seems that dietary patterns in the Middle East and North Africa changed significantly between 1961 and 2007. Increased availabilities of energy, sugar and caloric sweeteners, meat, milk and dairy products in these regions represent the changes in dietary pattern from conventional diets to a Westernized diet that are associated with a high burden of chronic diseases. Further country-level investigations of the dietary trends in these regions are suggested.

\section{Acknowledgements}

This research received no specific grant from any funding agency in the public, commercial or not-for-profit sectors. There are no conflicts of interest to declare. P.M. and M.J. developed the project idea for the study. M.G., P.M., M.M. and F.A. designed the project. M.G., P.M., M.J. and K.T. analysed and interpreted the data. M.G., P.M., M.J., K.T. and F.A. prepared the manuscript. All authors read and approved the final submitted version of the manuscript. The authors would like to express their appreciation to Ms N. Shiva for language editing of the manuscript and Dr Bahram Rashidkhani for his assistance in statistical analyses.

\section{References}

1. Drewnowski A \& Popkin BM (1997) The nutrition transition: new trends in the global diet. Nutr Rev 55, 31-43.

2. Madanat HN, Troutman KP \& Al-Madi B (2008) The nutrition transition in Jordan: the political, economic and food consumption contexts. Promot Educ 15, 6-10.

3. Popkin BM (2009) Global changes in diet and activity patterns as drivers of the nutrition transition. Nestle Nutr Workshop Ser Pediatr Program 63, 1-10.

4. Atinmo T, Mirmiran P, Oyewole OE et al. (2009) Breaking the poverty/malnutrition cycle in Africa and the Middle East. Nutr Rev 67, Suppl. 1, S40-S46.

5. Galal O (2003) Nutrition-related health patterns in the Middle East. Asia Pac J Clin Nutr 12, 337-343.

6. Bermudez OI \& Tucker KL (2003) Trends in dietary patterns of Latin American populations. Cad Saude Publica 19, Suppl. 1, S87-S99.

7. Hawkes C (2006) Uneven dietary development: linking the policies and processes of globalization with the nutrition transition, obesity and diet-related chronic diseases. Global Health 2, 4.

8. Patel MS, Srinivasan M \& Laychock SG (2005) Nutrientinduced maternal hyperinsulinemia and metabolic programming in the progeny. Nestle Nutr Workshop Ser Pediatr Program 55, 137-147.

9. Hosseinpanah F, Barzin M, Sheikholeslami F et al. (2011) Effect of different obesity phenotypes on cardiovascular events in Tehran Lipid and Glucose Study (TLGS). Am J Cardiol 107, 412-416. 
10. Hosseinpanah F, Barzin M, Eskandary PS et al. (2009) Trends of obesity and abdominal obesity in Tehranian adults: a cohort study. BMC Public Health 9, 426.

11. World Health Organization (year) WHO Global Infobase, NCD Indicators. http://apps.who.int/infobase/Indicators. aspx?ISO3=dza (accessed September 2011).

12. World Health Organization (2011) Global Status Report on Noncommunicable Diseases 2010. Geneva: WHO.

13. Reddy KS (2002) Cardiovascular diseases in the developing countries: dimensions, dynamics and directions for public health action. Public Health Nutr 5, 231-237.

14. World Health Organization (2002) WHO Vaccine-Preventable Diseases: Monitoring System. Geneva: WHO.

15. Hosseini-Esfahani F, Jessri M, Mirmiran P et al. (2010) Adherence to dietary recommendations and risk of metabolic syndrome: Tehran Lipid and Glucose Study. Metabolism 59 , 1833-1842.

16. Ghassemi H, Harrison G \& Mohammad K (2002) An accelerated nutrition transition in Iran. Public Health Nutr 5, 149-155.

17. Mehio Sibai A, Nasreddine L, Mokdad AH et al. (2010) Nutrition transition and cardiovascular disease risk factors in Middle East and North Africa countries: reviewing the evidence. Ann Nutr Metab 57, 193-203.

18. Noah A \& Truswell S (2003) Commodities consumed in Italy, Greece and other Mediterranean countries compared with Australia in 1960s and 1990s. Asia Pac J Clin Nutr 12, 23-29.

19. Schmidhuber J \& Traill WB (2006) The changing structure of diets in the European Union in relation to healthy eating guidelines. Public Health Nutr 9, 584-595.

20. Mazzocchi M, Brasili C \& Sandri E (2008) Trends in dietary patterns and compliance with World Health Organization recommendations: a cross-country analysis. Public Health Nutr 11, 535-540.

21. World Health Organization (2003) Diet, Nutrition and the Prevention of Chronic Diseases. Joint WHO/FAO Expert Consultation. WHO Technical Report Series no. 916. Geneva: WHO.

22. Food and Agriculture Organization of the United Nations (2011) Food Balance Sheets. http://www.faostat.fao.org/ site/368/default.aspx (accessed November-December 2010).

23. Da Silva R, Bach-Faig A, Raidó Quintana B et al. (2009) Worldwide variation of adherence to the Mediterranean diet, in 1961-1965 and 2000-2003. Public Health Nutr 12, 1676-1684.

24. Vareiro D, Bach-Faig A, Raidó Quintana B et al. (2009) Availability of Mediterranean and non-Mediterranean foods during the last four decades: comparison of several geographical areas. Public Health Nutr 12, 1667-1675.

25. Balanza R, García-Lorda P, Pérez-Rodrigo C et al. (2007) Trends in food availability determined by the Food and Agriculture Organization's food balance sheets in Mediterranean Europe in comparison with other European areas. Public Health Nutr 10, 168-176.

26. Petrovici D (2004) An Exploratory Analysis of European Food Consumption Patterns. Working paper no. 37. Canterbury: Canterbury Business School.

27. US Department of Agriculture \& US Department of Health and Human Services (2005) Dietary Guidelines for Americans. http://www.health.gov/dietaryguidelines/ dga2005/document (accessed February 2011).

28. Garcia-Closas R, Berenguer A \& González CA (2006) Changes in food supply in Mediterranean countries from 1961 to 2001. Public Health Nutr 9, 53-60.

29. Caballero B (2006) The nutrition transition: global trends in diet and disease. In Modern Nutrition in Health and Disease, 10th ed., pp. 1719-1720 [ME Shils, editor]. Philadelphia, PA: Lippincott Williams and Wilkins.

30. Scagliusi FB, Ferriolli E \& Lancha Jr AH (2006) Underreporting of energy intake in developing nations. Nutr Rev 64, 319-330.

31. Hu FB (2008) Globalization of food patterns and cardiovascular disease risk. Circulation 118, 1913-1914.

32. Pomerleau J, Lock K, McKee M et al. (2004) The challenge of measuring global fruit and vegetable intake. J Nutr 134, $1175-1180$.

33. Hung HC, Joshipura KJ, Jiang R et al. (2004) Fruit and vegetable intake and risk of major chronic disease. $J$ Natl Cancer Inst 96, 1577-1584.

34. Ledoux TA, Hingle MD \& Baranowski T (2011) Relationship of fruit and vegetable intake with adiposity: a systematic review. Obes Rev 12, e143-e150.

35. Popkin BM \& Gordon-Larsen P (2004) The nutrition transition: worldwide obesity dynamics and their determinants. Int J Obes Relat Metab Disord 28, Suppl. 3, S2-S9.

36. Popkin BM (2002) The shift in stages of the nutrition transition in the developing world differs from past experiences! Public Health Nutr 5, 205-214.

37. Minihane AM \& Harland JI (2007) Impact of oil used by the frying industry on population fat intake. Crit Rev Food Sci Nutr 47, 287-297.

38. Kittler PG \& Sucher KP (2008) Food and Culture, 5th ed., pp. 417-428. Belmont, CA: Thomson Wadsworth.

39. Willett WC, Sacks F, Trichopoulou A et al. (1995) Mediterranean diet pyramid: a cultural model for healthy eating. Am J Clin Nutr 61, 6 Suppl., 1402S-1406S.

40. Dodd J (2008) Nutrition in adult years. In Krause's Food and Nutrition Therapy, 12th ed., pp. 269-285 [LK Mahan and

S Escott-Stump, editors]. Philadelphia, PA: Saunders.

41. Satia JA (2010) Dietary acculturation and the nutrition transition: an overview. Appl Physiol Nutr Metab 35, 219-223.

42. Proietti AR, del Balzo V, Dernini S et al. (2009) Mediterranean diet and prevention of non-communicable diseases: scientific evidences. Ann Ig 21, 197-210.

43. Sofi F, Cesar F, Abbate R et al. (2008) Adherence to Mediterranean diet and health status: meta-analysis. BMJ 337, a1344.

44. Tyrovolas S \& Panagiotakos DB (2010) The role of Mediterranean type of diet on the development of cancer and cardiovascular disease, in the elderly: a systematic review. Maturitas 65, 122-130.

45. Kastorini CM, Milionis HJ, Goudevenos JA et al. (2010) Mediterranean diet and coronary heart disease: is obesity a link? - A systematic review. Nutr Metab Cardiovasc Dis 20, 536-551.

46. The World Bank (2011) GDP (current US\$). http:// data.worldbank.org/indicator/NY.GDP.MKTP.CD (accessed September 2011). 
Appendix

\section{List of selected food items from food balance sheets}

\begin{tabular}{|c|c|c|}
\hline 1. Cereals - excluding beer & Sesame seed & Dates \\
\hline Wheat & Palm kernel & Grapes \\
\hline Rice & Olive & Fruits, other \\
\hline Maize & Oil crops, other & 10. Alcoholic beverage \\
\hline Rye & 7. Vegetable oils & Wine \\
\hline Oats & Soyabean oil & Beer \\
\hline Millet & Groundnut oil & Beverages, fermented \\
\hline Sorghum & Sunflower seed oil & Beverages, alcoholic \\
\hline Cereals, other & Rape and mustard seed oil & Alcohol, non-food \\
\hline 2. Starchy roots & Cotton seed oil & 11. Meat \\
\hline Cassava & Palm kernel oil & Bovine meat \\
\hline Potatoes & Palm oil & Mutton and goat meat \\
\hline Sweet potatoes & Coconut oil & Pig meat \\
\hline Yams & Sesame seed oil & Poultry meat \\
\hline Roots, Other & Olive oil & Meat, other \\
\hline 3. Sugar and sweeteners & Rice bran oil & 12. Animal fats \\
\hline Sugar, non-centrifugal & Maize germ oil & Butter, other \\
\hline Sugar (raw equivalent) & Oil crops, other & Cream \\
\hline Sweeteners, other & 8. Vegetables & Fats, animals, raw \\
\hline Honey & Tomatoes & Fish, body oil \\
\hline 4. Pulses & Onions & Fish, liver oil \\
\hline Beans & Vegetables, other & 13. Eggs \\
\hline Peas & 9. Fruits - excluding wine & 14. Milk - excluding butter \\
\hline Pulses, other & Oranges, mandarins & 15. Fish and seafood \\
\hline 5. Tree nuts & Lemons, limes & Freshwater fish \\
\hline 6. Oil crops & Grapefruits & Demersal fish \\
\hline Soyabean & Citrus, other & Pelagic fish \\
\hline Groundnut & Bananas & Marine fish, other \\
\hline Sunflower seed & Plantains & Crustaceans \\
\hline Rape and mustard seed & Apples & Cephalopods \\
\hline Cotton seed & Pineapples & Molluscs, other \\
\hline
\end{tabular}

